\title{
Conceptualising equity in the impact evaluation of chronic disease management programmes: a capabilities approach
}

\author{
Ina Tapager* (D), Kristian Schultz Hansen and Karsten Vrangbæk \\ Department of Public Health, Center for Health Economics and Policy, University of Copenhagen, Kobenhavn, Denmark \\ *Corresponding author. Email: iwt@sund.ku.dk
}

(Received 18 April 2019; revised 27 January 2020; accepted 14 February 2020; first published online 24 April 2020)

\begin{abstract}
Chronic diseases are highly important for the future level and distribution of health and well-being in western societies. Consequently, it seems pertinent to assess not only efficiency of chronic care but also its impact on health equity. However, operationalisation of health equity has proven a challenging task. Challenges include identifying a relevant and measurable evaluative space. Various schools of thought in health economics have identified different outcomes of interest for equity assessment, with capabilities as a proposed alternative to more conventional economic conceptualisations. The aim of this paper is to contribute to the conceptualisation of health equity evaluation in the context of chronic disease management. We do this by firstly introducing an equity enquiry framework incorporating the capabilities approach. Secondly, we demonstrate the application and relevance of this framework through a content analysis of equity-related principles and aims in national chronic disease management guidelines and the national diabetes action plan in Denmark. Finally, we discuss how conceptualisations of equity focused on capabilities may be used in evaluation by scoping relevant operationalisations. A promising way forward in the context of chronic care evaluation may emerge from a combination of concepts of capabilities developed in economics, health sciences and psychology.
\end{abstract}

Key words: Chronic disease; diabetes; health economic evaluation; health equity; outcomes measurement

\section{Introduction}

Chronic diseases are highly important for the future level and distribution of health and well-being in western societies. Thus, it seems pertinent to assess not only efficiency of chronic care but also its impact on health equity. However, while equity in health as a general concept has 'nearly universal ethical appeal' and is reflected in health policy agendas worldwide, its conceptualisation and assessment remains less straightforward (Giacomini and Hurley, 2008: 285). It has been argued that the main contribution of economics to decision making in health care happens through the concepts of efficiency and equity as criteria to judge the use of scarce health care resources - but "there is far less agreement within economics about equity than about efficiency" (Morris et al., 2007: 18). The lack of consensus or clarity is not limited to the arena of health economics but is a general issue, with practical implications for measurement as well as policy (Braveman, 2006). Recent reviews have pointed to the multitude of definitions and approaches - and significant challenges - in dealing with health equity and social justice in health economic contributions to decision making in health care (Lane et al., 2017; Dukhanin et al., 2018).

To evaluate the extent to which resource allocation is equitable "depends on the moral underpinnings of the community's particular commitment to equity" (Giacomini and Hurley, 2008:

(C) The Author(s), 2020. Published by Cambridge University Press. This is an Open Access article, distributed under the terms of the Creative Commons Attribution licence (http://creativecommons.org/licenses/by/4.0/), which permits unrestricted re-use, distribution, and reproduction in any medium, provided the original work is properly cited. 
292). It has been suggested that empirical investigations should be "preceded or related to the health equity objectives which particular countries reveal and interpreted in the light of rigorous normative formulations", and preferably specifying them in a way to enable positive analysis (Pereira, 1993: 44). The importance of clarifying and being transparent about the social value judgements involved in economic evaluation and the necessity of being concerned with distributional issues have also been emphasised by e.g. Culyer and Wagstaff (1993); Brouwer et al. (2008) and Asaria et al. (2013). Such efforts include determining the relevant evaluative space.

The capabilities approach to identifying the relevant evaluative space for an equity-focused evaluation (Sen, 1982, 1993, 2002) has long been of interest to researchers and policy-makers in a vast array of interdisciplinary settings (Robeyns, 2005a). It has also made significant advances in the health economics arena over the last few decades; through direct application (Coast et al., 2008b, 2015a; Ruger, 2010a; Mitchell et al., 2015) and indirectly through its influence on the extra-welfarist paradigm (Brouwer et al., 2008; Culyer, 2012). The capabilities approach is a broad normative framework for evaluating the goodness of various societal arrangements and its applications span different disciplines, aims and methodologies (Robeyns, 2005a, 2005b). The core characteristic is a focus not on happiness or desire-fulfilment, income or consumption, but directly on capabilities: what people are able to do or be; their ability to flourish and lead lives they have reason to value (Sen, 1982; Ruger, 2010a). It emphasises the different capacities people have for transforming goods and services into capabilities and hence also different resources needed to promote equal capabilities (Sen, 1982; Robeyns, 2005a; Ruger, 2010a). In the context of chronic illness there is a particular appeal in this focus on potentiality: the abilities and freedom to achieve health functioning even in the presence of a pre-existing condition (Ruger, 2010a: 77). However, the approach is broad and 'requires specification before operationalizing it' (Ruger, 2010a: 58) and such specification efforts have led to different interpretations and different assessments of measurement possibilities. Despite differences, the theoretical and methodological reflection sparked by a capabilities approach is argued to further the health economics discipline (Coast et al., 2015b).

The right choice of methods to monitor and judge equity impacts of health programmes will depend on the nature of equity concerns: what should be distributed, how, and to what end? (Giacomini and Hurley, 2008). We propose that the field of chronic care resource allocation policies such as for diabetes is a particularly relevant case for investigating a capabilities approach to evaluating equity impact due to the potential long-term impact on the entire life situation of patients and ongoing (self-)care needed to minimise morbidity and mortality over a life course. Further, diabetes pinpoints many of the general dilemmas associated with health equity enquiries: the interaction between society and individual in causes and consequences of disease and the difficulties in separating and addressing health differences resulting from free choice vs social or biological constraints (Giacomini and Hurley, 2008).

In this paper, we aim to develop further the conceptualisation of health equity evaluation in the particular context of chronic care, and diabetes in particular. We do this by firstly introducing an equity enquiry framework incorporating a capabilities approach to health equity evaluation. Secondly, we apply this framework to guide a content analysis of Danish national guidelines for chronic disease management programmes (DMPs) and the national diabetes action plan, i.e. centrally decided principles of allocation of care resources, to investigate the equity-related aims and principles as revealed from these and relate these to the normative formulations of the equity framework. Finally, we discuss how such considerations may inform an evaluative framework by scoping relevant paths to operationalisation.

Much of the conceptual work on health equity deals with health and health policy in very general terms. We suggest that applying theoretical conceptualisation to a specific health issue (diabetes) and the associated care policies may help bridge the gap between theoretical deliberations and practical applications in health equity studies. As argued by Johri and Norheim (2012: 130): "Achieving greater clarity at the conceptual level will facilitate effective data gathering on the 
equity effects of interventions" - we hope to offer some useful insights for endeavours along this path from normative discussion to positive analysis.

While the analysed policy documents are Danish, the discussion on equity is not unique to a Danish context, neither is the application of equity analysis in the field of DMP and diabetes care appraisal. Therefore, this paper may be of general interest for researchers of health equity, public health policy and health economics outcome measurement as well as for researchers concerned specifically with equity assessment in the field of DMPs and diabetes.

\section{An equity analysis framework}

The general concept of health equity requires "that patients who are alike in relevant respects be treated in like fashion and that patients who are unlike in relevant respects be treated in appropriately unlike fashion" Culyer (2001: 276). These principles of 'like' and 'appropriately unlike' treatment are termed as horizontal and vertical equity (Culyer, 2001; Morris et al., 2007; Giacomini and Hurley, 2008). The concept of vertical equity may be further specified as treating those who are unlike differently "in proportion to their relevant differences" (Culyer and Wagstaff, 1993; Giacomini and Hurley, 2008: 285; both tracing the origins to Aristotle). In the context of health systems, this implies that goods such as health services should be distributed according to "meaningful and relevant differences among individuals" (Giacomini and Hurley, 2008: 287). Gaining more specificity to the general concept of horizontal and vertical equity depends on the meanings of relevant differences and appropriately different treatment (Culyer, 2001; Giacomini and Hurley, 2008). Indeed, in terms of like and unlike treatment the "similarity or differences involved do not follow from the principle of equity, but are instead something that the principle of equity has to presuppose; so everything depends on how those similarities and differences are defined" (Weale and Clark, 2010: 244).

A subsequent relevant question is: like or unlike treatment to what end? There is no consensus regarding what aspect in the health delivery and outcome chain is the key to describing an equitable end-state allocation of resources (Lane et al., 2017). Braveman and Gruskin (2003) noted that the concept of equality is indispensable when operationalising equity since it offers the ability to assess empirically the equality of some measurable outcomes. However, while there is consensus that an equitable distribution implies some form of equality (or elimination of some types of inequalities), it is not universally accepted what should be equalised (Culyer, 2001; Lane et al., 2017). Indeed, it has been suggested that the title question posed in Sen's paper 'Equality of what?' may form the relevant question to evaluate different conceptions of equity in health (Smith and Normand, 2011). Main contenders include: equal health ${ }^{1}$ as a means to enable equal ability to 'flourish' in life (Culyer and Wagstaff, 1993; Culyer, 2001, 2015), equal (or fair) opportunity to health (Whitehead, 1992 and in a different formulation; Roemer, 2013) and equal (basic) capabilities (Sen, 1982; Pereira, 1993). Common to these outcomes are, that they cannot be distributed or redistributed directly among individuals in society and policy is thus left with distributing determinants such as access to health interventions. To determine whether such efforts succeed in promoting equity, it is necessary to form an idea of what an ideal distribution would look like (Giacomini and Hurley, 2008).

Culyer (2001: 277) refers to 'macro equity' as being concerned with 'the equity of the distribution of health care across categories of persons deemed relevant'. Subscribing to this focus of analysis and summarising the reflections above, a model for a macro equity enquiry in health policy is sketched in Figure 1. For simplicity, assume two categories of recipients of care $A$ and $B$ respectively. To promote the health of groups $A$ and $B$, society can offer a possible set of health care interventions (commodities) $X_{A}$ and $X_{B}$. The concepts of horizontal and vertical equity will require either like or unlike treatment according to relevant personal characteristics of $A$ and $B$,

${ }^{1}$ With certain conditions attached, e.g. while not deliberately deteriorating the health of some. 
Figure 1. An equity enquiry framework.

Source: Own illustration based on the above reviewed literature.

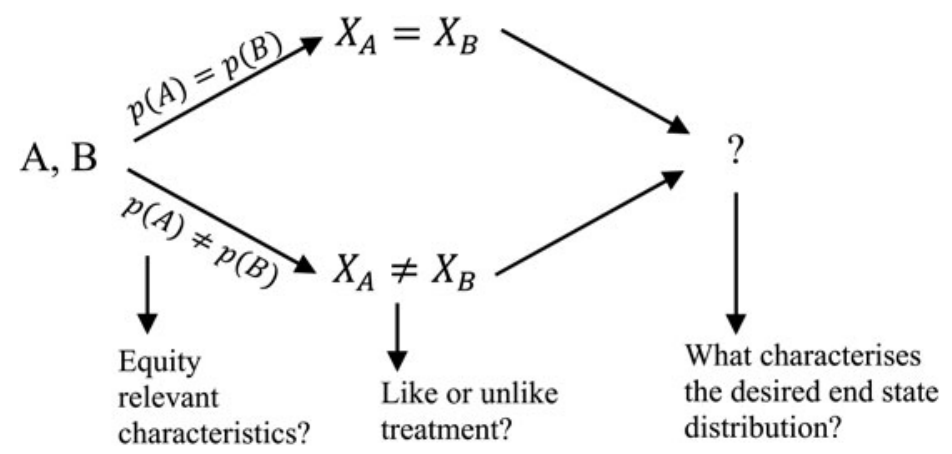

which may be termed $p(A)$ and $p(B)$. Finally, the evaluation of equity aims should include an enquiry into what characterises the desired end-state distribution, including what end-state outcome is of key interest to judge equity. In this framework, an enquiry into equity aims includes looking at the principles of allocation of resources and their possible justification in terms of a desired end-state.

The last part of Figure 1 includes identifying the relevant outcomes measure(s) to analyse in terms of evaluating equity. To clarify the concepts in play in characterising the desired end-state (unfolding the last part of Figure 1), some notation may work as a point of departure [adapted from Sen (1999, orig. 1987) and later adaptations (Pereira, 1993; Alkire, 2005a; Culyer, 2012)]:

- Let $x_{i}$ be the health-related commodities (health care) used by individual $i$, belonging to a set of possible options $X_{i}$ available to individual $i$ and

- $c\left(x_{i}\right)$ is a function determining the characteristics of $x_{i}$ (e.g. clinical efficacy, timeliness etc.)

- A person has personal features $F_{i}$ determining her conversion of characteristics into functionings. That is, a person can obtain a particular health functioning $h_{i}=f_{i}\left(c\left(x_{i}\right)\right)$, with $f_{i}\left({ }^{*}\right) \in F_{i}$.

- The total freedom or capability that individual $i$ has to generate health functionings given personal features (conversion) $F_{i}$ and command over health commodities $X_{i}$ available to the individual can be expressed as:

$$
Q_{i}\left(X_{i}\right)=\left[h_{i} \mid h_{i}=f_{i}\left(c\left(x_{i}\right)\right) \text {, for some } f_{i}() \in F_{i} \text { and some } x_{i} \in X_{i}\right] \text {. }
$$

- The value of health functionings may be assessed by a valuation function $v_{i}=v_{i}\left(h_{i}\right)$ which could be interpreted in terms of well-being and could be evaluated for a particular function$\operatorname{ing} h_{i}^{*}, v_{i}\left(h_{i}^{*}\right)$.

We suggest, that in the context of evaluating equity in chronic care, the equity-related actions (like or unlike treatment) may be understood as the set of health-related commodities made available $\left(X_{i}\right)$, e.g. a set of treatment options and rehabilitative measures as described in treatment programmes. The effect on individual health functioning will depend on what is utilised $\left(x_{i}\right)$ and the extent to which this is transformed into health given the personal features and conditions of the individual and thus differences in ability to convert available resources into achieved functioning. The total capabilities "represent the alternative combinations of things a person is able to do or be - the various 'functionings' he or she can achieve" (Sen, 1993: 30). Among this capability set, choices are made by the individual resulting in a set of achieved functioning.

Figure 2 exhibits a graphical representation of the above framework and shows that a capabilities approach to health can bind together the spectrum from health care input (provision) in one end over conversion and choice among possibility set and ending in achieved functioning and a 


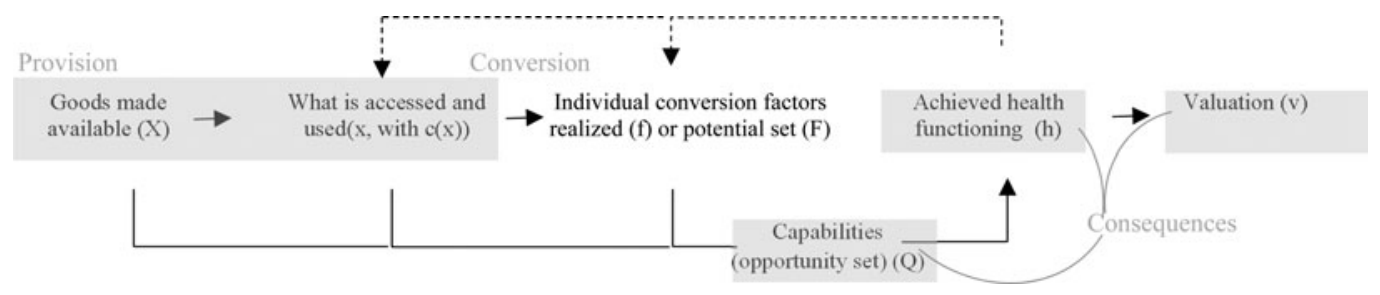

Figure 2. To what end? Possible end-state objects of interest in the health delivery-outcome chain. Source: Own illustration, drawing on expositions in Pereira (1993: 42); Sen (1999: 7); Robeyns (2005a: 98); Culyer (2012: 56). Note: Dashed lines indicate a potential circularity in the sense that improvements in functioning may affect later choices and freedoms. If considering a set of functionings generally (or a set of different functionings within the health domain), an improvement in one functioning, may affect capabilities to achieve other valuable functionings. For instance, an improvement in psychosocial functioning may improve capabilities for improving or maintaining physical health functioning.

possible valuation of this state. In accordance with the capabilities theory, the framework implies attention to individual conversion factors. That is, that even with the same health care input characteristics, individuals may differ in their ability to convert this into achievement, thus resulting in different consequences (Chiappero-Martinetti et al., 2019).

Figure 2 highlights the several options for outcomes of interest in equity analysis along this health delivery and outcome chain revealed from the health equity literature (see e.g. reviews in Braveman, 2006; Lane et al., 2017). One may be interested in what is offered $\left(X_{i}\right)$ or what is accessed and used $\left(x_{i}\right)$. Such focus would emphasise the significance of fairness in the process of health delivery or a goods-oriented approach to equity. A counter-argument by Sen (1982) is that an isolated goods focus would disregard the variability of people's conversion of goods to capabilities to achieve valued outcomes. Also, resources such as health care may be seen not as intrinsically valuable but valuable as instruments for enhancing people's capabilities for health achievement (Ruger, 2010a).

A more outcome-oriented (consequentialist) focus could emphasise the distribution of achieved health $\left(h_{i}\right)$ and its valuation $\left(v_{i}\right)$. A focus on achieved health may be justified on account of its special importance for ability to 'flourish in life' (Culyer and Wagstaff, 1993; Culyer, 2001), but has been criticised for potentially implying unacceptable discrimination in provision of care to reduce inequality, if used as the only metric for evaluating equity in health (Sen, 2002). Further, an evaluation of achieved functioning (like health) or its individual valuation in terms of wellbeing would disregard the element of freedom and enablement distinctive of the capabilities perspective (Sen, 1999; Alkire, 2005a).

A utilitarian type outcome may be defined as the satisfaction or happiness derived from the achieved health functioning, or directly from the use of health care offerings. Normative theory in health economics often discusses the divide of a welfarist vs non- or extra-welfarist perspective (Brouwer et al., 2008; Coast et al., 2008b). A focus on health or capabilities or even a preferencebased valuation function ranking of achieved health by e.g. quality-adjusted life-years (QALYs), may be justified from an extra-welfarist position (Brouwer et al., 2008; Culyer, 2012), whereas welfarism is associated exclusively with a metric of individual utilities (Brouwer et al., 2008). A welfarist utility metric of evaluation, however, is not uniquely defined but can inter alia be interpreted in terms of preference-satisfaction, experienced happiness/satisfaction or in monetary terms (Sen, 1999; Cookson, 2005; Coast et al., 2008b). The lines between different approaches to identifying the 'right' evaluative space are thus not self-evident. A capabilities approach to health equity assessment will find an isolated focus on either provision of health care or consequences (e.g. health functioning or utility) inadequate to address the multidimensional nature of health equity (Sen, 2002; Ruger, 2010a, 2010b). For example, the evaluative space in a capabilities approach might include health resources, conversion, achieved and potential health functioning whereas welfarism would focus on individual end-state utilities. 
For simplicity, the exposition in Figure 2 does not include outside influences like social norms in people's living environment. However, social context may likely influence individual means and freedom to achieve as well as the preferences and choices made, and hence both capabilities and achievement (Robeyns, 2005a). This implies that a full account of equity impacts may have to look for interactions beyond health and beyond the limits of an individual.

For analysing health policy objectives about health equity, the above reviewed theory leaves us with a framework of different criteria determining like or unlike treatment and for the outcomes and processes deemed of interest to determine an equitable end-state (Figures 1 and 2). Health policy may likely reference several different equity-related concerns (Hurley, 2015), which our application of a content analysis in the next section will illustrate.

\section{Applied equity aims analysis}

This section investigates the equity-related aims and principles as revealed from the centrally decided principles of allocation of care resources in the context of disease management and diabetes in particular, and relates these to the perspectives presented in the equity framework of the previous section.

\subsection{Setting}

Denmark has a tax-financed public health care system where the general planning, regulation and supervision takes place at a central level by the Ministry of Health and the national health authorities. Currently, five regions are responsible for hospital, specialist and general practitioner services and the 98 municipalities comprised in these regions have a range of responsibilities concerning prevention, rehabilitation and long-term care (Vrangbæk, 2016). Care for many major chronic diseases is organised across sectors according to DMPs inspired by the American chronic care model (Frølich et al., 2015). DMPs describe a multidisciplinary approach to care for patients with chronic diseases including several intervention components and coordination across health care delivery systems aiming at the management of a particular chronic condition (Ellrodt et al., 1997; Weingarten et al., 2002). DMPs have been implemented in health care systems worldwide with the general aims to "enhance quality and continuity of care for the chronically ill, whilst making efficient use of healthcare resources" (de Bruin et al., 2011: 105). The Danish national strategy for care of chronic patients in the form of DMPs was launched in 2008 including diabetes as the first disease specific programme. In the process of forming these national guidelines an advisory board was formed including appointed representatives for health professionals, patient organisations and decision makers and the first programme was submitted for public hearing in 2007 (Danish Health Authority, 2008).

The Danish Health Authority led the policy process, coordinated and published the generic DMP guidelines, that have since been concretised and implemented by regional and municipal authorities (Frølich et al., 2015), with on-going revisions. The actual content, organisation and implementation may thus vary geographically but not the essential features and principles (Danish Health Authority, 2008; Frølich et al., 2015). In its own words, the generic DMP model constitutes 'a conceptual framework' for DMPs in Denmark (Danish Health Authority, 2012: 5). In 2017, a national action plan for diabetes was released by the Ministry of Health (2017). The plan describes the updated strategic plans for future diabetes care, i.e. the general aims and ideas, not the detailed execution.

In Denmark, diabetes is among the 10 diseases contributing most to education based inequality in burden of disease as well as among the 10 diseases contributing most to the overall burden of disease in Denmark (Diderichsen et al., 2012: 26).

\subsection{Methods}

The documents studied here are the initial national DMP guideline documents on the general framework as well as diabetes specific guidelines from 2008 and the revised national DMP 
document of 2012 (Danish Health Authority, 2008, 2012). The 2012 version aimed to update and include the experiences to date in the document while keeping with the main features (Danish Health Authority, 2012: 3). These DMP documents guided the implementation of DMPs with diabetes as the first chronic disease around which these ideas developed and took form. In addition, we look at the national diabetes action plan (Ministry of Health, 2017) representing current policy aims in relation to diabetes care and equity. The documents are chosen as reflections of the overall rhetoric in terms of strategic aims and principles of allocation of chronic care, with diabetes as a main case, spanning the last decade. In addition, these documents have implications in terms of prescribed actions for practices of care. However, it is beyond the scope of the present analysis to evaluate the translation of equity-related aspirations to specific actions at the regional/ municipal levels.

We applied a directed content analysis guided by the equity enquiry framework described in part 1, with the aim of verifying the existence of equity-related concerns and elaborating on the nature of such concerns and with a specific interest in distinguishing the types of features that may inform subsequent operationalisation based on the theoretical framework and policy content in combination. Directed content analysis can be used to "validate or extend conceptually a theoretical framework" (Hsieh and Shannon, 2005: 1281) and has previously been applied in the context of health policy analysis (Kelly et al., 2016; Schang et al., 2016). Categories were formed based on the equity framework described above and synthesised in Figures 1 and 2, thus identifying statements relating to: (1) equity-related actions: like or unlike provision based on individual or group characteristics, (2) what these equity-relevant characteristics are considered to be and (3) the overarching aims in terms of desired end-state outcomes. Within this overall structure of three main categories, sub-categories were formed to offer more specificity in the groupings of findings. For actions (ad 1), simply the like and unlike treatment. For characteristics (ad 2), a separation between those situated in the health domain and those spilling over to other domains. This distinction arose during the initial reading and familiarising of the texts. The sub-categories of outcome aims description ( $\operatorname{ad} 3$ ) followed the formalisation summarised in Figure 2, separated in groupings concerning: provision, health conversion functions and the three types of consequences: health itself, capabilities and individual valuation or utility. Recognising the inherent broadness of the term capabilities and its theoretical roots, the capabilities category was further specified in terms of looking for the distinguishing features of capabilities, i.e. the notion of ability and freedom to pursue valued functioning (health or otherwise), capability in its 'potential sense' (Ruger 2010a: 77). While this approach offered direction, a broad perspective was applied when identifying how the content and characteristics of these main- and sub-categories were reflected in the texts. This process draws on directed content analysis as described by Hsieh and Shannon (2005) (albeit in the context of interview research) and document content analysis more generally (Bowen, 2009; Prior, 2014).

\subsection{Findings}

The categories and summary of findings are displayed in Table 1.

\subsubsection{Like or unlike treatment}

The overarching principle of allocation was that of providing care according to need. This concept is embedded in the DMP model's central principle of stratification: allocating patients to different types and intensities of care according to need: "The differing needs of patients require health services that are adapted to groups of patients, a so-called stratified effort" (Danish Health Authority, 2008: 26, 52, and similar wording in 2012: 11).

A concern for like treatment for like characteristics is reflected in two ways: through a consistent focus on uniformity of care practices and quality thereof (mainly stated in terms of geography and referenced in all documents) and by describing the pathway of care and the matching of 
Table 1. Content analysis of equity-related concerns: summary of findings

\begin{tabular}{|c|c|c|}
\hline Category & Sub-categories & Aims and principles \\
\hline \multirow[t]{2}{*}{$\begin{array}{l}\text { Equity-relevant actions: } \\
\quad \text { like or unlike treatment }\end{array}$} & Like treatment & $\begin{array}{l}\text { Concerns over uniformity of care practices and quality } \\
\text { thereof. Stratification procedures in DMPs prescribe } \\
\text { like treatment for like needs. }\end{array}$ \\
\hline & Unlike treatment & $\begin{array}{l}\text { Needs-based provision of care. Tailored and targeted } \\
\text { programmes of care. }\end{array}$ \\
\hline \multirow[t]{2}{*}{$\begin{array}{l}\text { Equity-relevant } \\
\text { characteristics }\end{array}$} & Health domain & $\begin{array}{l}\text { Illness characteristics defining care levels (severity, } \\
\text { prognosis, multi-morbidity, etc.) }\end{array}$ \\
\hline & ....and beyond & $\begin{array}{l}\text { 'Vulnerability' and influence of personal resources, } \\
\text { social context, and demography. }\end{array}$ \\
\hline \multirow[t]{6}{*}{ To what end? } & Provision & $\begin{array}{l}\text { Uniform and cohesive health care provision: } \\
\text { availability of equal treatment options } \\
\text { geographically (procedural concerns). }\end{array}$ \\
\hline & & $\begin{array}{l}\text { Ensuring 'optimal' use of resources and addressing } \\
\text { resource constraints (efficiency concerns). }\end{array}$ \\
\hline & $\begin{array}{l}\text { Health production/ } \\
\text { conversion factors }\end{array}$ & $\begin{array}{l}\text { Emphasis on improvement in risk-profiles and } \\
\text { heterogeneity in self-care abilities of patients. }\end{array}$ \\
\hline & Health outcomes & $\begin{array}{l}\text { Maximise health outcomes, minimise (risk of) health } \\
\text { deterioration, complications, etc. Reduce/address } \\
\text { social and geographical inequalities in health. }\end{array}$ \\
\hline & Capabilities & $\begin{array}{l}\text { Focus on rehabilitation and education efforts to } \\
\text { enable people to choose according to own values } \\
\text { and goals to support independent and meaningful } \\
\text { lives. Emphasis on abilities to reduce health risks. }\end{array}$ \\
\hline & Valuation/utility & $\begin{array}{l}\text { Improve patient satisfaction and consider patient } \\
\text { preferences for treatment. }\end{array}$ \\
\hline
\end{tabular}

Source: Summarised selected content (Danish Health Authority, 2008, 2012; Ministry of Health, 2017).

needs with treatment (mainly in the DMP documents). The focus on providing (unlike) treatment types and intensities according to need is consistent in all documents, however with a tendency for increased emphasis on individual (rather than group-based) tailoring over time. This may be taken to implicate a focus on the likeness of the types of treatment available for access: "All patients with diabetes should have access to treatment of the same high quality" (Ministry of Health, 2017: 41) but with a potentially very wide space of actual utilised care pathways.

The documents thus offer supporting evidence for the general concept of equity in allocation in terms of horizontal and vertical equity in a needs-based interpretation: like treatment for like needs and unlike treatment for unlike needs. However, while this general principle may seem trivial, the unfolding of the determinants of need in the documents hint to the complexities of operationalising 'need' and thus the characteristics determining an equitable provision (see below).

\subsubsection{Equity-relevant characteristics}

The determinants of need, and thus the equity-relevant characteristics determining like or unlike treatment (Figure 1), may be found in the health domain and beyond. The characteristics include a wide range of possible determinants and are mentioned throughout the documents in various, sometimes overlapping, terms. A specific section on stratification mentions both illness-related characteristics and measurable health outcomes as well as elements such as "physical, social and attitudinal environment" and personal factors such as "social status, marital status, vulnerability, coping ability and life experience" (Danish Health Authority, 2012: 55). There is a specific focus on targeting and customising content to the needs of "vulnerable patients": a term used to 
describe a particular subset of patients who are characterised by being "heavily dependent on health and/or social services" and/or because of "weak personal resources and poor or different understanding of disease, social or cultural circumstances are incapable of performing suitable behaviour and self-care" (Danish Health Authority, 2008: 23, 50, and similar in 2012: 14). The care policies thus reflect a concern for the least advantaged in terms of capabilities for health - and to some extent socioeconomic disadvantage in general. The above also highlights attention to people's differential conversion factors as criteria for determining resource allocation.

The criteria for allocation to different treatment intensities are occasionally found to be defined somewhat endogenously in the guidelines: "chosen criteria [for stratification] should have prognostic significance or decisive impact on which health professional intervention the patient needs". The concretisation in the diabetes specific part convey a focus on clinically measurable criteria and no explicit mention of how to deal with the psychosocial or environmental determinants described in the general model (Danish Health Authority, 2008). The documents reflect related but different conceptualisations of characteristics determining unlike treatment: (1) a general model of differentiated care according to need (stratification to care groups, (2) an (other) type of targeted and customised intervention for a group of 'vulnerable patients' with 'special needs' and (3) individually tailored pathways of care - tailored to various individual characteristics (Danish Health Authority, 2008, 2012; Ministry of Health, 2017).

\subsubsection{To what end?}

The overall aims of the Danish DMPs correspond to the original DMP model of improving quality and continuity of care and promoting health and preventing deterioration while ensuring efficient use of resources. Stratification to care types and intensities is justified in terms of satisfying different patient groups' needs, obtaining optimal health outcomes and securing 'appropriate' or 'effective' use of resources.

In terms of end-state distribution, all documents reference a need to address socially related inequalities in health. In the DMP documents, this is mainly addressed indirectly through the emphasis on response to differential needs and abilities for self-care. The latest diabetes action plan contains more explicit aims of reducing social and geographical health inequalities, e.g. that the physician's effort 'should to a larger extent reflect the individual patient's risk profile, thus supporting greater equality in health'.

Rehabilitation and supporting self-care through education feature prominently in the DMP guidelines. Here, the outcome aims go beyond a conception of health to a more general sense of wellbeing and autonomy, that: "a citizen who has - or is at risk of - serious impairments in physical, psychological and/or social functioning, achieves an independent and meaningful life" (Danish Health Authority, 2008: 20). The content also reflects objectives relating to supporting the patient's ability to act to improve health: "to marshal and utilise personal resources to cope with chronic illness and perform self-care" (Danish Health Authority, 2012: 13). It also references more clearly an aim of supporting the ability to act as an agent of own (health) goals: "to give the patient knowledge and skills together with the ability to make conscious choices according to own values and aims" (Danish Health Authority, 2008: 46). Such content was grouped in the capabilities category due to its emphasis on ability and freedom to act and transform resources to valued outcomes whereas concerns over patient preferences and patient satisfaction were grouped as reflecting utility-related outcomes (Table 1).

\subsubsection{Summing up}

In this section, we set out to verify the existence of equity-related concerns and elaborate on the nature of such concerns in health policy documents describing resource allocation principles in chronic disease management and diabetes care specifically. The analysis reflects a diversity of principles and aims of resource allocation of relevance to equity assessment. Concerns include equality of access and quality, distribution of resources according to need, including a concern 
for alleviating health inequalities by allocating extra resources to those with poorer health risk profiles or 'vulnerable' who are less able to convert own and health care resources to improve health functioning. In terms of relevant outcome measure(s), the documents reflect a diverse collection of objectives, including a concern with both health in itself and a much broader conception of well-being autonomy, including self-care skills as emphasised perceived necessary means to achieve valued outcomes.

In the context of chronic disease management evaluation, it appears from the document analysis, that it is important to address both health functioning, and the abilities and potential for coping with lifelong (and changing) illness demands, of mobilising own resources to pursue good health and valued living. And in terms of equity: to apply particular efforts to those judged to be poorly off in these respects. This emphasis on enablement would appear to support a capabilities perspective to health equity because of its broad focus on the entire continuum from command over health care to differential conversion and differential ability and freedom to pursue health (Ruger, 2010b). It may be argued that such concerns could be reflected in some construction of individual utility or well-being functions. However, this would imply disregarding any intrinsic value to the equity of such aspects and only grant value in terms of their contribution to realised individual utility (or health if operating in a health-focused evaluation scheme). Evaluating individual well-being or realised health is not incompatible with the framework of chronic care presented in the health policy documents studied here. Yet, it appears insufficient as it neglects several features which are, on the other hand, given significance in a capabilities approach.

\section{Cross-disciplinary scoping of relevant methods of operationalisation}

The previous two sections have reviewed and formed a framework for analysing health equity concerns and applied this to policies of chronic care management (and diabetes, in particular) using Denmark as the case example. In this section, we discuss possibilities for empirical evaluation by scoping the literature on operationalising health equity outcomes from a capabilities perspective based on the findings in the previous sections.

\subsection{Operationalising multiplicity}

The review in the previous section suggests that policies on chronic care management tend to encompass many types of concerns in terms of both allocative principles and resulting outcomes. This observation of multiple equity-related aims and principles is not unique to this Danish context (Smith and Normand, 2011). It is also not surprising given the broadness of the concept of equity and its application in health as presented in Section 2. Consequently, it seems that evaluation of equity impacts should be based on a rich evaluative space such as a multi-criteria approach, as promoted by Hurley (2015).

The richness and content of the evaluative space identified from the policy-perspective seem compatible with the deliberate broadness of a capabilities perspective on measurement (Coast et al., 2008b). The separation of capabilities from other categories of outcome in the content analysis (Table 1) was made to simplify presentation but may be a little artificial considering the broadness of the concept as reviewed in Section 2, i.e. that capabilities represent the total opportunity set of achievable functioning. It can thus be seen to encompass both individual command over health inputs, possibilities for conversion into health and a sense of freedom or independence to pursue valued lives, including achievement of good health functioning. In that sense, a capabilities framework for evaluation would appear compatible with key tenets of the chronic care policies presented in the previous section. However, it would seem necessary for such an approach to reference these various aspects from health care input over conversion to capabilities and outcomes (Figure 2) for a full account of equity in accordance with the revealed equity aims of the chronic care policies. 


\subsection{Towards measurement}

The broadness and interdisciplinary nature of Sen's capabilities theory does not lend itself easily to immediate empirical application. Sen has remarked that "There is often good sense in narrowing the coverage of capabilities for a specific purpose" (Sen, 2004: 79). It has been suggested that the selection of measures should be judged on its relevance to the evaluative purpose and on criteria of importance and influenceability (Alkire, 2005a), and further, that "when the capability approach is applied to particular research questions, we might prefer lists that are derived from, are embedded in, and engage with the existing literature in that field" (Robeyns, 2005b: 201). Below, we discuss the existing types of measurement operationalisations and their applicability to the policies and context of chronic care management analysed in this paper.

Through four distinctive reviews (Alkire, 2005b; Robeyns, 2006; Coast et al., 2015a; Mitchell et al., 2017) and two key supplementary conceptualisations (Cookson, 2005; Ruger, 2010b) of quantitative measures of capabilities, we identified four types of operationalisation approaches relevant for measuring capabilities in the context of health care intervention assessment (elaborated below):

(1) Specifically developed instruments to capture a self-reported measurement of capabilities

(a) Defined from a priori lists (e.g. Lorgelly et al., 2015)

(b) Developed using participatory approaches aimed to measure a subjective well-being aspect of capabilities (e.g. Coast et al., 2008a; Al-Janabi et al., 2012)

(2) Re-interpretation of the QALY framework to constitute and index value of capabilities (Cookson, 2005)

(3) Measuring the freedom or agency aspect explicitly using self-reported measures developed from psychological theories of capabilities and human agency (Alkire, 2005b)

(4) A 'health capability profile' based on a broad mix of indicators on internal and external factors of health functioning and capability, self-reported and otherwise (Ruger, 2010b)

Specific instruments have been developed in expert-led and participatory approaches (Coast et al., $2015 a$ ). The theory or expert-led approaches include efforts to select and combine measures from existing surveys to fit with a philosophically founded list of essential capabilities forwarded by theorist Martha Nussbaum (Anand et al., 2009; Lorgelly et al., 2015). Without entering the discussion on the merits of a pre-defined list or not [see discussion in Robeyns (2005b)], it can be noted here, that the content of these, would seem to go well beyond the concerns reflected in the chronic care policies reviewed here, e.g. by questions on other species and imagination, freedom of political expression and safety (Lorgelly et al., 2015).

Others have focused on developing new self-reported measures of capabilities (instruments reviewed in Coast et al., 2015a, 2015b). Some have been developed as quality of life instruments through a qualitative participatory process (Coast et al., 2008a; Al-Janabi et al., 2012), focusing on identifying on "what was important to individuals in their lives" (Al-Janabi et al., 2012: 168), resulting in different measures designed for different age groups (the ICECAP-Older people and ICECAP-Adult, respectively). This presumably implies a dependence on the features and context of the subjects involved in the development, which could challenge the task of evaluating in other settings and in the context of recipients of chronic care, encompassing a large age-span and life conditions, social class and culture. Also, while the deliberate focus in the ICECAP measures on well-being and on moving beyond health outcomes in evaluation (Coast et al., 2015a) may partially reference some concerns of the chronic care policies analysed in the previous section, it would seem inadequate to address the dominant focus on outcomes directly relatable to health and health behaviour.

Cookson's capabilities reinterpretation of the existing QALY measurement (Cookson, 2005) speaks to a health outcomes focus in evaluation. QALYs are often used in health economic evaluation as a generic measure of health using an "acceptable and systematic rule to rank health 
states" (Brouwer et al., 2008: 332). However, such a measurement of health status (and associated valuation of health status) would not seem to address directly people's capabilities for pursuing health and reducing risks - only indirectly through their present general health attainment. Health functioning measurement - though not necessarily conceptualised as in the QALY framework - may be seen as a proxy for capabilities, as "in most situations, health achievement tends to be a good guide to the underlying capabilities, since we tend to give priority to good health when we have the real opportunity to choose" (Sen, 2002: 660).

In the context of development economics, Alkire $(2005 a, 2005 b)$ has reviewed avenues of cross-disciplinary efforts to advance measurement options for the capability approach, exploiting relevant co-developments in other disciplines. Her line of enquiry focuses on how to capture the elusive human agency and freedom element of Sen's capabilities approach in self-reported measurement. In this quest, she brings in various approaches to identifying an agency aspect of wellbeing from different disciplines, psychology in particular. Agency is understood as people's ability to act on behalf of what matters to them and has both intrinsic value as part of one's well-being and instrumental value in its capacity to bring about positive change (Alkire, 2005b: 223). Alkire (2005a) proposes to combine measures of functionings and measures of 'autonomy or process freedoms'. As an approach to measure such agency or freedom aspects empirically, Alkire $(2005 b, 2005 a)$ points to various theories and constructs, among these Bandura's theory of human agency and self-efficacy (Bandura, 1995) - a psychologically founded view of human agency and capabilities. This view on capabilities stresses the role of personal agency in the sense of making causal contributions to individual functioning (Bandura, 1995; Schwarzer and Fuchs, 1995). As in Sen's work, personal agency is not limited to strict self-interest or individual utility and the language of people's 'capability to produce valued outcomes' feature also in this theoretical setting (Bandura, 1995: 1). Such capabilities are argued to depend on people's sense of self-efficacy: "If people believe that general means to solve a problem must exist, they scrutinize their capability for appropriate actions and watch out for the best means available to them only if they feel capable" (Schwarzer and Fuchs, 1995: 279). Schwarzer and Fuchs (1995: 261) further define perceived self-efficacy as being "concerned with people's beliefs in their capabilities to perform courses of action required to attain a desired outcome".

The concept of self-efficacy is already established in the context of evaluating chronic DMPs, particularly regarding aims of self-management interventions such as patient education to improve the abilities of people in living with chronic diseases. It is emphasised among evaluation measures due to its perceived instrumental value in bringing about positive change in health behaviour and health (Steuten et al., 2006; Lemmens et al., 2008; Tsiachristas et al., 2014). Self-efficacy can be operationalised by various instruments that may be more or less domain and behaviour specific. A generalised measure could be justified both when covering an intervention set and health condition that influences a range of behaviours and coping outcomes (Luszczynska et al., 2005) and for reflecting a broad sense of capability freedom without being set on exactly what is valuable activities or states of being.

The issue of combining multiple measures of functioning and agency aspects for a full description of capabilities has been described specifically for the health domain by Ruger $(2010 a, 2010 b)$. In her 'health capability paradigm', Ruger argues for focusing on central health capabilities: "people's capability to avert premature mortality and escape morbidity" (Ruger, 2010a: 43) and "how well individuals can act as agents of their own health" (Ruger, 2010b: 44). She describes a health capability framework integrating health outcomes and health agency and working with internal and external influences. As Alkire (2005b), Ruger (2010b) also points to the relevance of psychological measures, such as self-efficacy, to capture agency aspects. However, she also points to the need for addressing societal-level conditions that enable health in terms of individually differential impacts on abilities by group-level factors and describes an extensive list of factors to be included in a health capability profile, although allowing that "Different applications will require different measures" (p. 44). Her proposed framework speaks to many of the aspects of chronic 
care policies described here. However, the comprehensiveness may hint to practical challenges in measurement, comparison and aggregation not tackled yet.

\subsection{Health-related capability measurement in chronic care}

Efforts to integrate these various methodological advances may forward a more comprehensive evaluative space clarifying different types of effects and dimensions on which inequity may exist. Focusing on one absolute index measurement of consequences, exemplified by a scoring based on instruments such as the ICECAP (or QALYs in a re-interpreted role), would seem at odds with the multiplicity of aims and concerns of the capabilities approach as mirrored in the chronic care management programmes. There may on the other hand, be good sense in including both measurement of functioning and potential health capabilities (Ruger, 2010a) and it may be interesting not to aggregate measurements to not give up information on the nature and dimensions of possible inequalities (Robeyns, 2006).

Multi-criteria approaches to evaluation have been promoted in the context of chronic care DMPs (Lemmens et al., 2008; Tsiachristas et al., 2013), justified, however, in terms of the inherent multiplicity of components and aims in DMPs rather than to accommodate concerns over equity. Such approaches provide suggestions on how multiple elements can be included and evaluated together and relative to each other - including also concerns over efficiency (Johri and Norheim, 2012). However, pursuing a vast array of indicators (such as those in Ruger, 2010b) might prove too incalculable to translate to assessment. Hence, a possible middle ground may emerge from selecting a subset of key indicators from this framework. For the context of chronic care studied here, an application of the general idea of combined functioning and agency freedom measurement (Alkire, 2005b; Ruger, 2010b) could entail a combination of health status (e.g. through generic health status measures such as the EQ5D) and of self-efficacy and possibly other outcomes such as individual command of health care inputs, i.e. the access and quality of those. In a policy perspective, such a comprehensive and multidimensional measurement will highlight the need to focus chronic care interventions to explicitly address individual ability to access and convert health care resources to health outcomes. In other words, policy attention must consider equity in capabilities for dealing with chronic illness demands.

Generic measures will allow for comparison across disease domains and take the influence of comorbidities into account. Hence, a capabilities approach need not preclude inter-disease comparisons. However, for chronic conditions, people's health capabilities and aspects of agency may be of particularly salience for health equity due to the lifelong need for health services and selfcare and the interaction with non-health domains.

\section{Conclusions}

In this paper, we have aimed to develop further the conceptualisation of health equity evaluation in the context of chronic care. Discussions on equity go far back in time and although consensus may exist on some general features of equity, application in empirical questions of evaluation requires choices on content and criteria, including what types of outcomes to look to, and how to go about measurement. Our approach to determining a relevant evaluative space for an assessment of equity impacts included a deliberate process of three steps: forming a theoretical framework of analysis, an applied analysis of a decision-maker perspective and a scoping and discussion of options for measurement. We provided a summarised account of a health economic equity enquiry drawing on the conceptualisation of a capabilities approach to systematise a range of outcomes that may be relevant in the search for criteria to judge equity by. As one possible way to go from this framework to application, we analysed the equity-related aims and principles of allocation of care for chronic diseases (and diabetes, in particular) envisioned by centralised health planners in Denmark. This combination of a theoretical framework and analysis of the 
decision-maker perspective led us to a discussion of what types of outcomes should be assessed in terms of their distribution when evaluating equity of chronic DMPs.

The multiplicity and content of aims and allocation principles appeared to justify a broad evaluative space and confirm the relevance of including a capabilities perspective in such endeavours. A scoping of the methods on operationalisation of capabilities showed a broad range of interpretations even within this framework. The best match with the analysed chronic care policies appeared to lie in the efforts of combining health functioning and agency measures. The distribution on these measures could contribute to inform judgements on equity. However, the scope and implications of combined valuation of such elements as well as linkage to efficiency assessment is a further challenge to be tackled in the future. Neither health status measures nor agency measures such as self-efficacy are foreign to the sphere of chronic care evaluation but clarifying the conceptual as well as decision-maker justifications of use may facilitate future empirical work and interpretation.

Acknowledgements. The authors would like to acknowledge Signild Vallgårda and Hans Keiding for helpful comments on an earlier draft and Timothy Skinner for helpful discussions on capabilities and self-efficacy. This study has received funding from a research grant from the Novo Nordisk Foundation (EQUIP project). The funder had no role in the design, analysis or reporting. The views and interpretations expressed are solely those of the authors.

\section{References}

Al-Janabi H, Flynn TN and Coast J (2012) Development of a self-report measure of capability wellbeing for adults: the ICECAP-A. Quality of Life Research 21, 167-176.

Alkire S (2005a) Measuring the freedom aspects of capabilities. Harvard University, Global Equity Initiative (mimeo), 24.

Alkire S (2005b) Subjective quantitative studies of human agency. Social Indicators Research 74, 217-260.

Anand P, Hunter G, Carter I, Dowding K, Guala F and Van Hees M (2009) The development of capability indicators. Journal of Human Development and Capabilities 10, 125-152.

Asaria M, Griffin S and Cookson R (2013) Measuring health inequality in the context of cost-effectiveness analysis. In Dias PR and O'Donnell O (eds), Health and Inequality. Bingley: Emerald Group Publishing Limited, pp. 491-507.

Bandura A (1995) Exercise of personal and collective efficacy in changing societies. In Bandura A (ed.), Self-Efficacy in Changing Societies. Cambridge: Cambridge University Press, pp. 2-45.

Bowen GA (2009) Document analysis as a qualitative research method. Qualitative Research Journal 9, 27-40.

Braveman P (2006) Health disparities and health equity: concepts and measurement. Annual Review of Public Health 27, 167-194.

Braveman P and Gruskin S (2003) Defining equity in health. Journal of Epidemiology \& Community Health 57, $254-258$.

Brouwer WBF, Culyer AJ, van Exel NJA and Rutten FFH (2008) Welfarism vs. extra-welfarism. Journal of Health Economics 27, 325-338.

Chiappero-Martinetti E, Salardi P and Scervini F (2019) Estimating conversion rates: a new empirical strategy with an application to health care in Italy. Health Economics 28, 748-764.

Coast J, Flynn TN, Natarajan L, Sproston K, Lewis J, Louviere JJ and Peters TJ (2008a) Valuing the ICECAP capability index for older people. Social Science \& Medicine 67, 874-882.

Coast J, Smith RD and Lorgelly P (2008b) Welfarism, extra-welfarism and capability: the spread of ideas in health economics. Social Science \& Medicine 67, 1190-1198.

Coast J, Kinghorn P and Mitchell P (2015a) The development of capability measures in health economics: opportunities, challenges and progress. The Patient - Patient-Centered Outcomes Research 8, 119-126.

Coast J, Smith R and Lorgelly P (2015b) Should the capability approach be applied in health economics? Health Economics $17,667-670$.

Cookson R (2005) QALYs and the capability approach. Health Economics 14, 817-829.

Culyer AJ (2001) Equity - some theory and its policy implications. Journal of Medical Ethics 27, 275-283.

Culyer AJ (2012) Commodities, characteristics of commodities, characteristics of people, utilities and the quality of life. In Cookson R and Claxton K (eds), The Humble Economist: Tony Culyer on Health, Health Care and Social Decision Making. York: University of York and Office of Health Economics, pp. 55-66.

Culyer AJ (2015) Efficiency, equity and equality in health and health care. Centre for Health Economics, University of York. CHE Research Paper 120.

Culyer AJ and Wagstaff A (1993) Equity and equality in health and health care. Journal of Health Economics 12, $431-457$.

Danish Health Authority (2008) Forløbsprogrammer for kronisk sygdom - Generisk model og Forløbsprogram for diabetes [Disease Management Programmes for Chronic Illness - Generic Model and Disease Management Program for Diabetes]. Denmark: Sundhedsstyrelsen (Danish Health Authority). 
Danish Health Authority (2012) Forløbsprogrammer for kronisk sygdom: - den generiske model [Disease Management Programmes for Chronic Illness - The Generic Model]. Denmark: Sundhedsstyrelsen (Danish Health Authority).

de Bruin SR, Heijink R, Lemmens LC, Struijs JN and Baan CA (2011) Impact of disease management programs on healthcare expenditures for patients with diabetes, depression, heart failure or chronic obstructive pulmonary disease: a systematic review of the literature. Health Policy 101, 105-121.

Diderichsen F, Andersen I, Manuel C, Andersen A-MN, Bach E, Baadsgaard M, Brønnum-Hansen H, Hansen FK, Jeune B, Jørgensen T and Søgaard J (2012) Working Group of Danish Review on Social Determinants of Health. Health inequality - determinants and policies. Scandinavian Journal of Public Health 40, 12-105.

Dukhanin V, Searle A, Zwerling A, Dowdy DW, Taylor HA and Merritt MW (2018) Integrating social justice concerns into economic evaluation for healthcare and public health: a systematic review. Social Science \& Medicine 198, 27-35.

Ellrodt G, Cook DJ, Lee J, Cho M, Hunt D and Weingarten S (1997) Evidence-based disease management. JAMA 278, 1687-1692.

Frølich A, Jacobsen R and Knai C (2015), Denmark. In Nolte E and Knai C (eds), Assessing Chronic Disease Management in European Health Systems: Country Reports. World Health Organization, European Observatory on Health Systems and Policies, pp. 17-26.

Giacomini M and Hurley J (2008) Issues in evaluating equity. In Potvin L and McQueen DV (eds), Health Promotion Evaluation Practices in the Americas: Values and Research. New York: Springer, pp. 285-298.

Hsieh H-F and Shannon SE (2005) Three approaches to qualitative content analysis. Qualitative Health Research 15, $1277-$ 1288.

Hurley J (2015) Reflecting on 'Equity in health care: the Irish perspective'. Health Economics, Policy and Law 10, $443-447$.

Johri M and Norheim OF (2012) Can cost-effectiveness analysis integrate concerns for equity? Systematic review. International Journal of Technology Assessment in Health Care 28, 125-132.

Kelly N, Garvey J and Palcic D (2016) Health policy and the policymaking system: a case study of primary care in Ireland. Health Policy 120, 913-919.

Lane H, Sarkies M, Martin J and Haines T (2017) Equity in healthcare resource allocation decision making: a systematic review. Social Science \& Medicine 175, 11-27.

Lemmens KMM, Nieboer AP, van Schayck CP, Asin JD and Huijsman R (2008) A model to evaluate quality and effectiveness of disease management. BMJ Quality \& Safety 17, 447-453.

Lorgelly PK, Lorimer K, Fenwick EAL, Briggs AH and Anand P (2015) Operationalising the capability approach as an outcome measure in public health: the development of the OCAP-18. Social Science \& Medicine 142, 68-81.

Luszczynska A, Scholz U and Schwarzer R (2005) The general self-efficacy scale: multicultural validation studies. The Journal of Psychology 139, 439-457.

Ministry of Health (2017) Den nationale diabeteshandlingsplan [The National Diabetes Action Plan]. Denmark: Ministry of Health (Sundheds- og ældreministeriet).

Mitchell PM, Roberts TE, Barton PM and Coast J (2015) Assessing sufficient capability: a new approach to economic evaluation. Social Science \& Medicine 139, 71-79.

Mitchell PM, Roberts TE, Barton PM and Coast J (2017) Applications of the capability approach in the health field: a literature review. Social Indicators Research 133, 345-371.

Morris S, Devlin N and Parkin D (2007) Economic Analysis in Health Care. Chichester; Hoboken, NJ: John Wiley \& Sons.

Pereira J (1993) What does equity in health mean? Journal of Social Policy 22, 19-48.

Prior L (2014) Content analysis. In Leavy P (ed.), The Oxford Handbook of Qualitative Research. Oxford University Press. 135. http://www.oxfordhandbooks.com/view/10.1093/oxfordhb/9780199811755.001.0001/oxfordhb-9780199811755-e-008.

Robeyns I (2005a) The capability approach: a theoretical survey. Journal of Human Development 6, 93-117.

Robeyns I (2005b) Selecting capabilities for quality of life measurement. Social Indicators Research 74, 191-215.

Robeyns I (2006) The capability approach in practice. Journal of Political Philosophy 14, 351-376.

Roemer JE (2013) Equity in health care delivery: Some thoughts and an example. In O'Donnell O and Dias PR (eds), Health and Inequality. Bingley, UK: Emerald Publishing Limited, pp. 471-489.

Ruger JP (2010a) Health and Social Justice. Oxford: Oxford University Press.

Ruger JP (2010b) Health capability: conceptualization and operationalization. American Journal of Public Health 100, 41-49.

Schang L, Thomson S and Czypionka T (2016) Explaining differences in stakeholder take up of disease management programmes: a comparative analysis of policy implementation in Austria and Germany. Health Policy 120, $281-292$.

Schwarzer R and Fuchs R (1995) Changing risk behaviors and adopting health behaviors: the role of self-efficacy beliefs. In Bandura (ed.), Self-Efficacy in Changing Societies. Cambridge: Cambridge University Press, pp. 259-288.

Sen A (1982) Equality of what?. In Sen (ed.), Choice, Welfare, and Measurement. Cambridge, Massachusetts: Harvard University Press, pp. 353-369

Sen A (1993) Capability and well-being. In Nussbaum M and Sen A (eds), Oxford: The Quality of Life. Oxford University Press, pp. 30-61.

Sen A (1999) Commodities and Capabilities. New Delhi, India: Oxford University Press.

Sen A (2002) Why health equity? Health Economics 11, 659-666. 
Sen A (2004) Capabilities, lists, and public reason: continuing the conversation. Feminist Economics 10, 77-80.

Smith S and Normand C (2011) 'Equity in health care: the Irish perspective. Health Economics, Policy and Law 6, $205-217$.

Steuten L, Vrijhoef B, Severens H, van Merode F and Spreeuwenberg C (2006) Are we measuring what matters in health technology assessment of disease management? Systematic literature review. International Journal of Technology Assessment in Health Care 22, 47-57.

Tsiachristas A, Cramm JM, Nieboer A and Mölken MR (2013) Broader economic evaluation of disease management programs using multi-criteria decision analysis. International Journal of Technology Assessment in Health Care 29, 301-308

Tsiachristas A, Cramm JM, Nieboer AP and Rutten-van Mölken MP (2014) Changes in costs and effects after the implementation of disease management programs in the Netherlands: variability and determinants. Cost Effectiveness and Resource Allocation 12, 17.

Vrangbæk K (2016) The Danish Health Care System, 2015. International Profiles of Health Care Systems, 2015. The Commonwealth Fund, pp. 39-47. Available at http://wwww.issuelab.org/resources/25100/25100.pdf.

Weale A and Clark S (2010) Co-payments in the NHS: an analysis of the normative arguments. Health Economics, Policy and Law 5, 225-246.

Weingarten SR, Henning JM, Badamgarav E, Knight K, Hasselblad V, Gano A and Ofman JJ (2002) Interventions used in disease management programmes for patients with chronic illness - which ones work? Meta-analysis of published reports. BMJ: British Medical Journal 325, 925.

Whitehead M (1992) The concepts and principles of equity and health. International Journal of Health Services: Planning, Administration, Evaluation 22, 429-445.

Cite this article: Tapager I, Hansen KS, Vrangbæk K (2022). Conceptualising equity in the impact evaluation of chronic disease management programmes: a capabilities approach. Health Economics, Policy and Law 17, 141-156. https://doi.org/ $10.1017 /$ S1744133120000067 